\title{
De la voz a la letra: Problemas lingüísticos en la transcripción de los relatos orales. I: La puntuación
}

El deseo de la viva voz habita toda poesía, y ésta se halla en exilio en la escritura.

Paul ZUMTHOR

\section{INTRODUCCIÓN}

El editor de relatos orales se encuentra en la necesidad de transformar en texto escrito el discurso que en origen era oral. Sometido a tal mutación del canal de transmisión, el texto, aunque conserva su identidad lingüística, cambia de naturaleza y de modo de recepción. Porque la escritura condiciona una recepción visual e individual por parte de un lector que maneja libre y globalmente el texto, pudiendo detenerse, avanzar o retroceder en su lectura y percibirlo como un todo.

El relato oral, sin embargo, se halla marcado por los rasgos propios de toda comunicación oral, y, en primer lugar, por la linealidad del signo lingüístico, que conlleva una percepción y una comprensión progresivas por parte de un oyente, que capta la unidad del texto exclusivamente en la medida en que éste se graba en su memoria. Precisamente con una función mnemónica, entre otras funciones, actúa el recurso formal más característico de la poesía oral: el ritmo (en el nivel de las recurrencias y los paralelismos y en el nivel prosódico) ${ }^{1}$. Nos referiremos aquí, de modo particular, a la edición de textos romancísticos, para analizar qué valores de la poesía oral se pierden al ser transcrita y qué recursos propios aporta la escritura para representar los hechos lingüísticos en un sistema gráfico.

1 El ritmo, en sentido amplio, concierne a la duración recíproca de los segmentos del discurso; dependiendo del nivel al que pertenecen dichos segmentos, se habla de ritmo en tres sentidos: a) ritmo narrativo y dramático: en el desarrollo de la acción de un relato o de una obra teatral; b) ritmo de las recurrencias y paralelismos: que produce efectos en el nivel de los motivos, de las frases, de las palabras, de los significados; c) ritmo prosódico: el de la manipulaciốn sonora de la lengua, que concierne a la entonación, las pausas, la duración - medida en sílabas - y el acento tónico. (En algunos casos, concierne a otros elementos prosódicos: el timbre, la altura y la intensidad). Aquí, nosotros emplearemos ritmo únicamente en el sentido de ritmo prosódico. 


\section{RITMO Y FUNCIONALIDAD DEL TEXTO ROMANCÍSTICO}

La grabación que realiza el moderno investigador de campo somete a un primer filtro a la palabra como acto en presencia: se pierden gran parte de la información extralingüística y la función primitiva del texto oral. En la transcripción se disocian, posteriormente, texto y melodía, cuando el relato es cantado, y se pierden, como en toda escritura, los valores de la voz particular del relator y la función comunicativa del ritmo prosódico y de las recurrencias.

El ritmo, cuya primacía es la particularidad más universal de los géneros literarios orales, sólo es expresivo y eficaz en el medio oral y auditivo. La distinción entre ritmo y metro, en los términos en que la establecieron en los años veinte los formalistas rusos Brik y Tomachevski ${ }^{2}$, aunque ya antigua, es esclarecedora y halla una justa aplicación en la poesía oral y, más concretamente, en el Romancero: el ritmo es movimiento únicamente existente en la oralidad; sólo el metro puede ser fijado por la escritura. Por ello, dice O. Brik:

Es necesario distinguir rigurosamente el movimiento del resultado del movimiento. Si una persona salta sobre un terreno pantanoso y deja sus huellas, aunque la sucesión de esas huellas sea regular, no constituye un ritmo. Los saltos se realizan según un ritmo, pero las huellas que éstos dejan sobre el suelo no son más que datos que sirven para juzgarlos. [...] Del mismo modo, el poema impreso en un libro no ofrece más que las huellas del movimiento. Sólo el discurso poético puede ser presentado como un ritmo y no su resultado gráfico. [...] El movimiento rítmico es anterior al verso. No se puede comprender el ritmo a partir de la línea de los versos; por el contrario, se comprenderá el verso a partir del movimiento rítmico ${ }^{3}$.

Para Brik, el metro es la forma establecida y fijada de un movimiento rítmico anterior a él, un movimiento que funciona como un sistema subyacente a la organización métrica ${ }^{4}$. Brik y Tomachevski ${ }^{5}$ desarrollaron, por ello, el concepto de impulso rítmico, que consideramos útil aplicar al romance.

2 Cf. Tzvetan TODOROv, Théorie de la littérature (Textes des Formalistes russes) (Paris: Seuil, 1965), pp. 143-169.

3 Ibid., p. 144.

4 Dicho en palabras de P. ZUMTHOR: "La mayoría de las culturas [...] recurren a sistemas rítmicos convencionales, cuyas normas están fundadas en costumbres musicales o lingüísticas", Introduction à la poésie orale (Paris: Seuil, 1983), p. 167. Porque -como dice Octavio PAz- «el ritmo no solamente es el elemento más antiguo y permanente del lenguaje, sino que no es difícil que sea anterior al habla misman, El arco $y$ la lira (México: Fondo de Cultura Económica, 3. ${ }^{a}$ ed., 1972), p. 68.

5 Ibid., pp. 145, 166-167. 
Uno de los aspectos que hay que contemplar en el estudio del verso - señala Tomachevski- es el del impulso rítmico, que rige la elección tipológica de las formas propias de un género. El impulso rítmico es diferente del metro porque: a) es mucho menos rígido que él; b) no define elecciones absolutas de formas, sino la preferencia por algunas de ellas; c) rige no sólo fenómenos conscientes y objetivados en la métrica tradicional, sino también fenómenos inconscientes que tienen un valor estético potencial; y d) concierne a leyes del ritmo del habla ${ }^{6}$.

A partir de esos principios, podemos establecer que:

1. Ia estructura métrica del texto romancístico la constituyen el esquema prosódico del dieciseisílabo, unidad binaria compuesta por dos grupos fónicos octosilábicos, y la recurrencia fónica de la rima asonante (admitiendo el "romance" versos de otras medidas).

2. El ritmo se expresa en la realización oral y en la repetición de dicho esquema prosódico, y es el elemento sonoro que hermana el texto romancístico con una melodía determinada.

3. El impulso rítmico que constituye el sistema subyacente a la organización métrica del romance aúna dos tendencias naturales del ritmo del habla: a) La del octosílabo, grupo fónico que se instaura como unidad recitativa mínima del romance y que es considerado afín al ritmo de la lengua española. Se trata de una composición silábica "muy pegadiza al

6 Véase una idea análoga de P. ZUMTHOR: “La prosodia de un poema oral refleja la prehistoria del texto dicho o cantado e interioriza el eco de su génesis prearticulatoria. Por ello, la mayoría de las performances, sea cual sea su contexto cultural, comienzan por un preludio no vocal: el golpeo de un objeto, un paso de danza o una medida musical preliminar. Así se expone el marco en el que va a expresarse la voz". "Le rythme dans la poésie orale", Le rythme et le discours, Langue française, 56, (1982), p. 114. Un caso particular de "preludio rítmico" —vocal, en esta ocasión- lo constituye el pie de romance, estribillo que acompaña siempre el canto de los romances en la isla canaria de La Gomera. Ese pie es un dístico octosilábico que debe hacer referencia a la fábula, al lugar, o al motivo por el que se canta, y cuya rima debe coincidir siempre con la rima del romance, del que es parte sustancial; "de forma que no se concibe el canto de un romance sin su correspondiente pie. De hecho, incluso cuando un informante inicia el recitado de un romance se resiste a empezar y titubea ostensiblemente a lo largo del relato si antes no ha encontrado el pie que le sirva de apoyo. Es que, como dicen humorísticamente algunos, sin pie no se puede caminar. M. TRAPERO, Romancero de la isla de la Gomera (Madrid: Cabildo Insular de La Gomera, 1987), p. 43. Cf., también, del mismo autor: Cultura popular y tradición oral: En busca de romances por La Gomera (Santa Cruz de Tenerife: Centro de la Cultura Popular Canaria, 1989), pp. 40, 45-46, 55-56, así como "Los estribillos romancescos de La Gomera: Su naturaleza y funcionalidad", Estudios de folklore y literatura dedicados a Mercedes Díaz Roig (México: El Colegio de México, 1992), pp. 127-145. 
oído del hispano-hablante" "; es "el pie métrico sobre el que camina toda la lengua española, prosa o verso" en palabras de Juan Ramón Jiménez ${ }^{8}$. b) La segunda tendencia, reflejada en la unidad binaria que constituye cada dieciseisílabo, es la tendencia rítmica de la poesía oral y de los proverbios hacia lo que Sánchez Romeralo llama un movimiento binario: "digo $\mathrm{A}$ y añado $\mathrm{B}$ ", movimiento "no basado en una concepción silábica, sino rítmica" ${ }^{9}$. (Obsérvese que esta última oposición entre silábica y rítmica refleja la misma distinción, anteriormente señalada, entre metro y ritmo ${ }^{10}$.

Únicamente en la oralidad cumple su función primitiva el ritmo creado por la repetición del esquema prosódico del romance: la "circularidad" del relato expresado en verso provoca la adhesión del oyente y coadyuva a la concentración del recitador o del cantor. El discurso sometido a la regularidad prosódica del metro favorece su memorización, primero por parte del difusor $\mathrm{y}$, posteriormente, por parte de los receptores ${ }^{11}$. El rit-

7 A. SÁnChez Romeralo, "Presencia de la voz en la poesía oral", El Romancero. Tradición y pervivencia a fines del siglo XX. Actas del IV Coloquio Internacional del Romancero, ed. de P. M. PiÑERO et al. (Sevilla-Cádiz: Fundación Machado-Universidad de Cádiz, 1989), p. 23.

8 Cit. por SÁNCHEZ ROMERALO, ibid. R. LAPESA habla de "preferencias características en cada idioman, en cuanto a la longitud de los grupos fónicos: "en español abundan especialmente los grupos de seis a nueve sílabas, que reúnen casi la mitad del total; dentro de ellos, los más favorecidos son los de siete y ocho sílabas". Introducción a los estudios literarios (Madrid: Cátedra, 1975), p. 58. Para NAVARro TOMÁs, "el octosílabo es sin duda el verso más antiguo de la poesía española" y "tiene sus raíces en la medida básica de los grupos fónicos de la lenguan, Métrica española (Madrid: Guadarrama, 1972), p. 71. Señala asimismo MENÉNDEZ PIDAl que «este verso de romance, cuando sobrevino el triunfo deslumbrador de los metros italianos, no pervivió obscuramente en la poesía oral, como un humilde tolerado, sino que se hizo invasor y poderoso; se le miró como el metro más natural del idioma", Los españoles en la literatura (Madrid: Espasa Calpe, Col. Austral, 1960), p. 39.

9 Ibid. Cf., también, del mismo autor: El Villancico (Estudios sobre la lírica popular en los siglos $x V y$ XVT) (Madrid: Gredos, 1969), p. 147.

10 A la distinción entre metro y ritmo se refiere Octavio PAZ cuando afirma que el metro es medida que tiende a separarse del lenguaje; el ritmo jamás se separa del habla porque es el habla misman (Op. cit., pp. 70-71). Cuando O. PAZ admite la posibilidad de que "los metros sean medidas inconscientes, al menos en ciertos casos" y que "el octosilabo español sería uno de ellos" (ibidem), está refiriéndose a lo que hemos llamado el impulso rítmico. Al considerar que, "como si obedeciesen a una misteriosa ley de gravedad, las palabras vuelven a la poesía espontáneamente» (ibid., p. 68), PAZ está describiendo lo que TOMACHEvski (loc. cit., p. 166) nombró aleyes del ritmo del habla".

11 Según las célebres palabras de MAÏAKOVSKI, eel ritmo constituye la fuerza magnética del poema" (cit. por P. ZUMTHOR, "Le rythme dans la poésie orale", op. cit., p. 115). O, como dice O. PAZ, «el ritmo es un imán» (op. cit., p. 53). En el seno de una 
mo del texto romancístico cumple en la oralidad lo que se ha llamado una "función de encantamiento del lenguaje" ${ }^{12}$. Ciertamente, la forma rítmica del romance es lo que le permite convertirse en un canto que acompaña y facilita el propio ritmo de los trabajos colectivos o de la tarea individual; o convertirse en base para un juego infantil; o en texto y motivo musical para un baile; o en texto religioso que desempeña una función de oración, la cual es un tipo de poesía que siempre ha recurrido a la eficacia de la repetición; o en canción de ronda, de marzas o de aguinaldos. El ritmo posee la regularidad temporal que invita a los oyentes a participar al unísono en el canto de un romance, cuando éstos repiten un mismo estribillo tras cada verso cantado por un solista. Este estribillo a veces hace referencia a la fábula, o al lugar, o al motivo por el que se canta el romance, pero, en otras ocasiones, no guarda relación alguna con el tema, ni informa de dato particular alguno; consiste más bien en un motivo para la expresión musical colectiva ${ }^{13}$.

La poesía oral rítmica, al manipular los elementos sonoros de la lengua natural mediante ciertos artificios, "crea un nivel auditivo secundario del lenguaje ${ }^{14}$, que puede ser un modo de expresión tan importante o más que el contenido mismo de los relatos ${ }^{15}$. Estos valores del ritmo

tradición cultural, esa fuerza se manifiesta en la extraordinaria resistencia que presentan las fórmulas rítmicas ante el deterioro causado por el paso del tiempo. "Más resistencia -explica ZuMTHOR (ibidem) - que cualquier otro elemento de la poesía (retórica, temas o, incluso, función social). El esquema prosódico y rítmico del romance constituye un caso modélico de pervivencia a través de los siglos y del dominio lingüístico hispánico.

12 Cf., entre otros: R. JAKOBSON, Ensayos de lingüística general. Traducción española de J. M. Pujol y J. Cabanes (Barcelona: Ariel, 1984, 3. ${ }^{a}$ ed.), O. PAZ (op. cit.), pp. 56 y 58) y P. ZuMTHOR, Introduction à la poésie orale, p. 159.

13 El estribillo es realmente un fenómeno más bien extraño al Romancero tradicional español. Cf. R. MENÉNDEZ PIDAL, Romancero Hispánico (2. ${ }^{a}$ ed.) (Madrid: EspasaCalpe, 1968), I, pp. 145-147). Sin embargo, es el elemento más característico del romancero canario: en algunas de las islas de Canarias, el canto del romance no se concibe si no es con su correspondiente estribillo. Cf. J. PÉREZ VIDAL, "Romances con estribillo y bailes romancescos", RDTP, IV (1968), pp. 197-241. Reproducido, con importantes ampliaciones, en El Museo Canario (Las Palmas de Gran Canaria, 1948), pp. 1-58, y recogido, por último, con el título "El estribillo en el romancero tradicional canario", en su libro Poesía tradicional canaria (Las Palmas de Gran Canaria: Cabildo Insular de Gran Canaria, 1968), pp. 9-75. Cf., también, M. TRAPERO, "Los estribillos romancescos de La Gomera: Su naturaleza y funcionalidad", op. cit.

14 P. ZumThOR, Introduction à la poésie orale (Paris: Seuil, 1983), p. 169.

15 En palabras de H. MESCHONNIC, el ritmo es uno de los amodos de significar que desbordan el signo", "Qu'entendez-vous par oralité?", Le rythme et le discours, 
podrían explicar, por ejemplo, el hecho de que en la fiesta de Santa Rosa de Lima, en el pueblo de Las Rosas, de la isla canaria de La Gomera, se cante un romance de incesto, el de Sildana, durante una procesión ${ }^{16}$. El tema del romance importa menos en ese acto religioso que el ritmo en el que se expresa, el cual acompaña el paso de la procesión y convoca a un mismo discurso a los asistentes, con un estribillo que dice:

\section{Santa Rosa, madre mia,}

boy se celebra tu día.

En la escritura, y fuera ya de su contexto sociocultural, el esquema prosódico del texto romancístico oral y su efecto rítmico carecen de su función y de su eficacia primitivas ${ }^{17}$. Nunca fue tan cierta como aplicada a la poesía oral transcrita en un libro la afirmación de Zumthor de que "el deseo de la viva voz habita toda poesía, y ésta se halla en exilio en la escritura" ${ }^{18}$. O la de Sánchez Romeralo cuando, refiriéndose a la oralidad, habla de "esa hermana menor, voraz, maravillosa fratricida, que es la escritura" ${ }^{19}$. Y es que, como este último autor dice, "trascrittori, traditori": ala fijación por escrito de un texto oral es siempre una forma de falseamiento de esa realidad [oral], ${ }^{20}$.

Langue française, 56 (1982), p. 8. O -como también dice O. PAZ- «el ritmo no es exclusivamente una medida vacía de contenido sino una dirección, un sentido" ( $o p$. cit., p. 57). Por ello, en algunas ocasiones es privilegiado de tal modo que "el cuerpo físico de la voz [puedel llegar a ser más importante que el sentido que la voz pretende transmitir. A. SÁnChez Romeralo, "Presencia de la voz en la poesía oral", p. 19. Han sido señalados numerosos casos de tradiciones orales en las que la poesía no transmite contenidos inteligibles, sino solamente sonidos y ritmos. ZUMTHOR cita, por ejemplo, ciertas tradiciones africanas (op. cit.), p. 114, pero más cerca aún, en nuestra propia tradición, podemos hallar buenos ejemplos en los dichos, poemas y retahílas infantiles.

16 Cf. M. TRAPERO, Cultura popular y tradición oral: En busca de romances por La Gomera (Santa Cruz de Tenerife: Centro de la Cultura Popular Canaria, 1989), especialmente, pp. 139-148.

17 El texto oral es por su propia naturaleza un texto en un contexto (nunca context-free). A. SÁNCHEZ ROMERALO (ibid.), p. 12.

18 Introduction à la poésie orale (Paris: Seuil, 1983), p. 160.

19 Ibid., p. 12.

20 A. SÁnchez Romeralo, "La edición del texto oral", La Edición de Textos. Actas del I Congreso Internacional de Hispanistas del Siglo de Oro. Ed. P. JAURALDE, D. Noguera y A. REY (Londres: Tamesis Books Limited, 1990), p. 73. 


\section{LA PROSODIA DEL ROMANCERO ORAL RECITADO}

La transcripción conlleva, en segundo lugar, una pérdida de la prosodia particular del recitador y, más concretamente, de la entonación.

Cuando el romance es cantado, el editor suele acompañar el texto de una transcripción musical de la melodía; sin embargo, para el texto recitado, la escritura no ofrece un sistema de notación de la entonación individual, la cual presenta la particularidad de ser diferente de la del lenguaje común, particularidad que pasa desapercibida en las colecciones de romances transcritos. De hecho, podemos establecer una cierta tipología de modos de recitación de textos romancísticos. Grosso modo: a) Una modalidad "tradicional", compartida por el difusor especializado y por todo recitador que haya memorizado su acervo romancístico por vía oral. b) Una modalidad "letrada" e "individual" de recitadores que aprendieron los textos a través de la escritura o que adaptan su prosodia a la de la aliteratura" escrita, dramatizando más el texto en algunos casos, y desvirtuando, en otras ocasiones, las unidades prosódicas propias del romance.

Este segundo modo de recitación, que encuentra el recopilador ocasionalmente, por ser individual, no encierra más importancia que la de indicar la vía escolar o libresca como formas de transmisión del romancero, mientras que la modalidad "tradicional" requiere otra reflexión por nuestra parte.

El texto romancístico es recitado generalmente, como hemos señalado, con una entonación distinta de la del discurso común ${ }^{21}$ : plana, monótona y de líneas melódicas fijas y comunes a todos los tipos de frases de un mismo texto; es decir, quedan neutralizadas las diferencias prosódicas entre frases declarativas, interrogativas y exclamativas.

21 Ello se constata claramente cuando el recitador interrumpe su relato para hacer alguna explicación sobre el texto. Por esta razón, algunos editores marcan tipográficamente tal diferencia: los comentarios prosificados de los informantes aparecen, no sólo entre paréntesis, sino también en cursiva. En un uso propio de la edición de relatos orales, la alternancia de caracteres tipográficos es marca distintiva de tipos de discurso (verso o prosa), producidos por un mismo locutor. Cf. M. TRAPERO, Romancero de Gran Canaria II, con un estudio de la música de L. SIEMENS HERNÁNDEZ) (Las Palmas de Gran Canaria: Cabildo Insular de Gran Canaria, 1990), p. 27. Citado, en adelante, con las siglas: GC II. Por ejemplo:

- Alevanta, Beneraldo, que ya seremos cogidos que mi padre ha dejado la espada de testigo.(Cuando el rey volvió para atrás le encontró que bajaba las escaleras) - ¿Qué traes, Beneraldo, que vienes tan descolorido?

(GC II, 5.11, vv. 8-10) 
Tampoco se aprovechan las múltiples posibilidades expresivas y significativas de la entonación, con las que cada hablante puede dotar a una misma frase. En realidad, todo discurso colectivo memorizado, tal como los rezos más frecuentes o como una simple tabla de multiplicar, tiende a ser repetido con una entonación estereotipada.

El lenguaje poético del romance se muestra "estilizado" ${ }^{22}$, no sólo en sus recursos formales y en el desarrollo de las fábulas, sino también en su prosodia. El recitador "tradicional" no interpreta, no dramatiza el texto. A pesar de lo dramático y lo trágico de muchas de las narraciones, la entonación permanece persistentemente plana. Ésta es una de las peculiaridades del lenguaje poético del romancero oral: la "gestualidad" y lo significativo de la entonación, que son manifestaciones de una interpretación y, por lo tanto, de una individualidad, se reducen al mínimo. La fuerza expresiva del texto romancístico radica exclusivamente en el movimiento rítmico, en el tratamiento dado a la fábula y en sus recursos poéticos propios para desarrollarla. En la recitación actúa sólo un esquema entonativo sencillo, que, por su facilidad para ser memorizado, se presta a pervivir inmutado y a pertenecer a la colectividad.

Por todo ello, constatamos que la prosodia del romancero oral también presenta rasgos de naturaleza comunitaria ${ }^{23} \mathrm{y}$, por tanto, de tradicionalidad $^{24}$. Como recuerda este autor, de la contextualidad del texto oral procede su carácter fragmentario, "fragmentario porque no llena por completo su espacio semántico, porque no es un texto semánticamente saturado" ${ }^{25}$. "Esa economía semántica —añade Sánchez Romeralo ${ }^{26}$ - encuentra correlación expresiva en la sintaxis, que Dámaso Alonso llamó sueltan. A ello hemos de añadir que tal economía semántica encuentra asimismo su equivalente en el ámbito prosódico de la performance, en los hábitos de recitación, puesto que no son empleadas todas las posibilidades significativas de la entonación.

22 ESTILIZAR: "Interpretar convencionalmente la forma de un objeto, haciendo resaltar tan solo sus rasgos más característicos" (DRAE 1984) o "...haciendo más delicados y finos sus rasgos" (según el DRAE 1992).

23 Término que tomamos de A. SÁnchez Romeralo, "Presencia de la voz en la poesía oral" (op. cit.), p. 21.

24 «El romance goza de una difusión y una estabilidad grandes, pero en grado inferior al lenguaje. Su brevedad, su forma fijada por el metro y por la melodía, le hacen fácil de retener en la memoria; lo aprenden y lo repiten muchos..... R. MENÉNDEZ PIDAL, Poesia juglaresca y juglares. Orígenes de las literaturas románicas (9. ${ }^{\mathrm{a}} \mathrm{ed}$.) (Madrid: Espasa-Calpe, Col. Austral, 1991), p. 461.

25 P. ZumThOR, op. cit., p. 56, cit. por A. SÁNCHEZ Romeralo, ibid., p. 19.

26 Ibidem. 
En esta modalidad de recitación del romancero de la tradición moderna se da lo que Luigi Allegri ha llamado una "convencionalidad comunicativa", refiriéndose al espectáculo en la Edad Media y al explicar cómo el juglar no daba una interpretación, sino una comunicación de los textos memorizados: no representaba, no personalizaba a los personajes, sino que únicamente los citaba, porque los instrumentos retóricos internos del texto ya debían ser suficientemente expresivos ${ }^{27}$.

El romancero oral se presenta ante nosotros quizá como el único género literario vivo que nos permita comprender aquella "convencionalidad comunicativa" de la oralidad, que fue el medio en el que se divulgó gran parte de nuestra literatura medieval ${ }^{28}$.

\section{PROSOdia y PUNTUACIÓN DEL TEXTO ROMANCístico}

La escritura no posee un sistema de representación de los valores fonoestilísticos de la prosodia de cada hablante, pero sí permite, con la puntuación, representar de modo simbólico estructuras suprasegmentales (entonación y pausas) que poseen, en numerosos casos, un valor distintivo y que dan cuenta de las diferentes modalidades de enunciados (declarativos, interrogativos, etc.).

Puesto que los editores de textos romancísticos no suelen, por lo general, indicar sus criterios de puntuación, nos proponemos presentar a

27 "El espectáculo en la Edad Media", Teatro y Espectáculo en la Edad Media. Actas Festival D'Elx (1990). Ed. de L. Quirante (Alicante: Diputación de Alicante, Inst. de Cultura "Juan Gil Albert", Ajuntament D'Elx, 1992), pp. 23-25.

28 Aún en nuestros días se encuentran algunos recitadores que parecen ser juglares vivos de la época medieval: son personas que han logrado traspasar el tiempo con una misma y monótona manera de "contar", como si desde la antigua épica al moderno romancero no hubiera habido más que continuidad. De uno de ellos, extraordinario en todos los sentidos, Pedro el ciego, de Estrada (Cervantes, Lugo), dimos noticia. M. TRAPERO, Cultura popular y tradición oral: En busca de romances por La Gomera, pp. 65-67. En otras tradiciones actuales de poesía memorial, podemos hallar también algún tipo de "convencionalidad comunicativa" en la recitación: la hallamos en la épica oral yugoslava. Cf. J. M FolEY, "Editing Oral Epic Texts: Theory and Practice", Text. Transaction of the Society for Textual Scholarship, 1 (Nueva York: AMS Press, 1981), p. 77. Y en otras tradiciones épicas como la mongol, la japonesa y la tibetana; en éstas últimas, “los aedas acostumbran a permanecer estáticos" y "la monotonía dota al espectáculo de cierta solemnidad. A. Rossell, "Canción de gesta y música. Hipótesis para una interpretación práctica: cantar épica románica hoy”, Cultura Neolatina, 51/3-4 (1991), p. 211. 
continuación algunas observaciones sobre diversas modalidades de transcripción y edición en cuanto a la puntuación y a sus valores. Nos interesa comprobar en los diferentes tipos de ediciones si la puntuación es representación gráfica fidedigna de la prosodia de los recitadores, o bien si se trata de signos requeridos por las "normas" ortográficas. Se plantea aquí la cuestión general de delimitar la frontera que separa los signos ortográficos con correspondencia prosódica, de aquellos signos de puntuación que funcionan dentro de un sistema propio de la escritura e independiente de la prosodia de la lengua hablada ${ }^{29}$.

\subsection{Disposición tipográfica del verso: el espacio en blanco}

4.1.1. Describiremos brevemente la estructura prosódica del romance, para analizar posteriormente los modos gráficos de transcripción de su unidad métrica.

El dieciseisílabo constituye una unidad sintáctico-semántica, cuya frontera métrica, marcada por la rima asonante, coincide con la frontera sintáctica y, por lo tanto, con una pausa en la recitación ${ }^{30}$. A su vez, la

29 Como producto propio de una cultura cada vez más letrada, el desarrollo de la puntuación medieval está ligado a las actividades de la traducción y de la exégesis, a la corrección de textos manuscritos en el scriptorium y a la lectura personal, prácticas todas ellas tendentes a alejarse de la oralidad. Aunque la puntuación tuvo desde la Antigüedad un carácter "respiratorio" de ayuda a la lectura vocalizada, numerosos comentarios de gramáticos y escritores medievales demuestran que, muy tempranamente, la puntuación fue también sentida como un sistema propio de ordenación de los mensajes en el código escrito. Cf., por ejemplo, M. B. PARKEs, "Punctuation, or Pause and Effect", Medieval Eloquence. Studies in the Theory and Practice of Medieval Rhetoric. Ed. de J. J. MURPHY (Berkeley - Los Ángeles - Londres: University of California Press, 1978), pp. 129-130. La independencia de algunos signos respecto a la prosodia se acentúa en la escritura impresa y, sobre todo, a partir del siglo xviII, cuando impresores y tipógrafos comienzan a imponer nuevos modos de puntuar y a enriquecer el repertorio con nuevos signos. En el actual sistema de normas ortográficas, tampoco se da una total correspondencia entre prosodia y puntuación, pues los signos funcionan en un sistema de organización sintáctica que no siempre representa los patrones prosódicos de entonación y pausas de la lengua oral.

30 Entre la versificación octosilábica de la canción popular, agrupando los versos en estrofas o "cuartetas", y la versificación de los romances viejos en dieciseisilabos hay toda una teoría contrapuesta que MENÉNDEZ PIDAL ha resuelto con un epígrafe muy ilustrativo: "La llamada cuarteta en los romances, mejor dicho pareado (op. cit.), p. 121. Y sigue diciendo el maestro indiscutible de la filología española: «Pero la cuarteta, o mejor dicho, dístico, no existió en la versificación de los romances viejos y populares, aunque la música con que más tarde se los solía cantar agrupase los octosílabos de 
unidad métrica y fonética de dieciséis sílabas está formada por dos grupos fónicos octosilabos, separados por una pequeña pausa ${ }^{31}$.

Por otra parte, si atendemos a las formas de combinación de texto y melodía en los romances cantados de la tradición moderna, constatamos que una frase musical corresponde siempre o bien a un dieciseisilabo, o bien a un octosílabo, siendo el tipo de estructura musical más frecuente el de cuatro frases musicales, correspondientes a cuatro octosílabos consecutivos ${ }^{32}$. Ello significa que la frase musical - unidad melódica- delimita y marca siempre o bien la unidad fónica y sintáctica del octosílabo, que es la base métrica del romance, o bien la unidad del dieciseisílabo.

Los musicólogos actuales, cuando transcriben las melodías de los romances, alternan entre conservar gráficamente la estructura de frases melódicas (por ejemplo, L. Siemens ${ }^{33}$ ), o escribir la melodía toda corrida (por ejemplo, M. Manzano ${ }^{34}$ ). Pero hay que tener en cuenta que texto romancístico y música con que se canta no siempre tienen estructuras paralelas, pues ni tuvieron el mismo origen ni el mismo desarrollo. "Cuando hablamos del canto romancístico en los siglos XV y XVI - dice Menéndez Pidal ${ }^{35}$-, veremos cómo la melodía musical para 32 sílabas [del romance] parece música ajena, pues se aplicaba a los romances muy a contrapelo de las pausas fraseológicas marcadas en la versificación".

4.1.2. Los editores modernos representan la estructura prosódica del romance por medio del primer recurso de la disposición tipográfica, que es el espacio en blanco.

cuatro en cuatro" (ibid., p. 123). Acerca de la cuestión del "verso de ocho sílabas o de dieciséis", véase D. DEvoto, "Sobre la métrica de los romances según el Romancero Hispánico", Cabiers de Linguistique Hispanique Médiévale, 4, (1979), pp. 5-50.

31 En ello, el dieciseisílabo del romance se comporta como cualquier oración de la lengua: "La oración, como verdadera unidad lingüística, constituye también una unidad fonética. El discurso se divide en oraciones separadas por pausas; estas oraciones, a su vez, también se dividen de ordinario en porciones menores - grupos fónicosseparadas por pausas. La pausa es siempre un momento de silencio; las pausas divisorias de oraciones son, en general, más largas que las divisorias de grupos fónicos, las cuales, en determinados casos, pueden llegar a ser sumamente breves". T. NAVARRO TOMÁs, Manual de pronunciación española (21. ${ }^{a}$ ed.) (Madrid: CSIC - RFE, 1982), p. 31.

32 J. DíAz, "La música en los romances", Euskera. Trabajos y actas de la Real Academia de la Lengua Vasca, 3 (1991), p. 872.

33 Cf. M. TRAPERO, GC II y Romancero de Gran Canaria, I, Zona del sureste (Agüimes, Ingenio, Carrizal y Arinaga), con un estudio de la música de L. SIEMENS HERNÁNDEZ (Las Palmas de Gran Canaria: Mancomunidad de Cabildos, 1982), citado, en adelante, con las siglas GC I.

${ }^{3 i}$ Cancionero leonés, (León: Diputación Provincial de León, 1991), vol. II, tomo I.

35 Op. cit., I, p. 123. 
En la gran mayoría de las colecciones romancísticas del siglo $\mathrm{xx}$, se considera como unidad métrica del romance el verso de dieciséis silabas. A cada verso se le asigna una línea - desde el punto de vista gráfico, un verso es una línea situada entre dos márgenes blancos- y se separan los octosílabos por un doble espacio en blanco, que es representación de la cesura y, por ello, verdadero signo de puntuación, empleado, a igual título que la coma o el punto y coma, para representar una pausa.

El esquema prosódico:

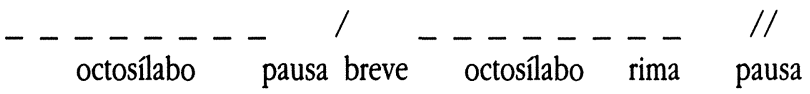

es representado del siguiente modo:

$$
\begin{aligned}
& \text { Pensativo está Rodrigo, } \\
& \text { por no poderse vengarivo y enroñado }
\end{aligned}
$$

Con el mismo valor que el doble espacio en blanco, algunos editores, como el mismo Menéndez Pelayo ${ }^{37}$ o como M. Díaz Roig, en una edición de romances muy divulgada, emplean el guión largo, tal como en estos versos:

$$
\begin{aligned}
& \text { Alli hablara el buen Cid, - de esta suerte respondiera: } \\
& \text { - Mas aquel que la tirare, - pase por la misma pena. } \\
& \text { - Idos de mis tiendas, Cid, - no quiero que estéis en ellas }{ }^{38} .
\end{aligned}
$$

Esta segunda modalidad, en nuestra opinión, puede estorbar a la lectura del texto, pues el guión largo suele aparecer en la misma posición con su función más común ${ }^{39}$ : la de indicar el inicio del discurso en estilo

36 GC II, 1.1, vv.1-2.

37 Antología de poetas líricos castellanos, VIII (Santander: Edición nacional de las obras completas de Menéndez Pelayo, XXIV, 1945).

38 M Díaz RoIG, El romancero viejo (3. ${ }^{a}$ ed.) (Madrid: Cátedra, 1978), p. 150, núm. 67 , vv. 11-13.

39 El lingüista francés C. TOURNIER atribuye a los "signos" de puntuación un significante y un significado, de tal forma que puede darse la "polisemia" en la puntuación, al existir significantes que poseen varios significados. "Histoire des idées sur la ponctuation, des débuts de l'imprimerie à nos jours", La ponctuation, Langue Française, 45 (1980), p. 36. Cf., también, N. CATACH, La ponctuation (Paris: PUF, Col. "Que sais-je?", 1994), pp. 96-97. El guión largo, por ejemplo, tiene en sus usos más frecuentes dos valores: a) marca de inicio de discurso directo (sin correspondencia prosódica) y b) marca de los incisos (con valor sintáctico y con correspondencia prosódica). A estos dos valores se les añadiría otro, con correspondencia prosódica: 
directo y el cambio de locutor. Se puede llegar incluso a grafías dobles del tipo:

—Mantengaos Dios, señor, - - Adalides, bien vengades ${ }^{40}$.

4.1.3. En época moderna, fue Grimm quien empleó por primera vez el verso largo, de dieciséis sílabas ${ }^{41}$, criterio que seguirían posteriormente

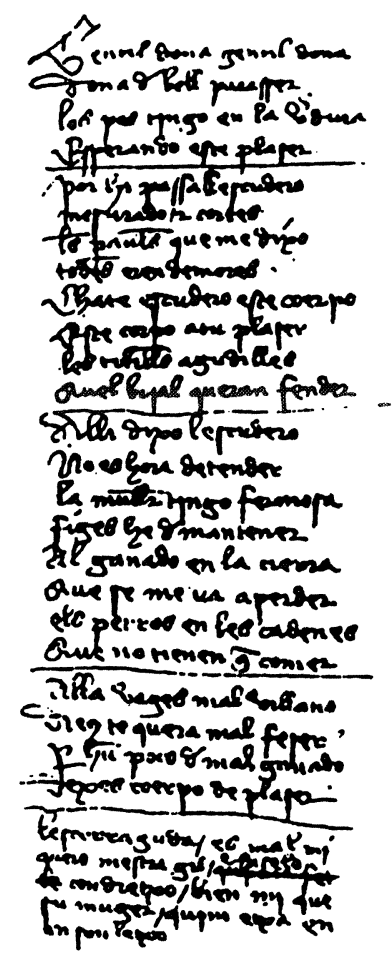

Milá y Fontanals y Menéndez Pelayo, entre otros editores del siglo XIX, y que consagró entre los editores del siglo $\mathrm{xx}$ el prestigio de Menéndez Pidal. El considerar como unidad métrica el verso largo permite distinguir el género romancístico del de la canción líri$\mathrm{Ca}^{42}$. En los Siglos de Oro, sin embargo, el romance se escribía siempre en versos cortos en los que se da como unidad métrica el octosilabo (ver textos 1a, 2 y 3), con la única excepción de Nebrija, que abogó por el verso largo.

Si comparamos el texto $1 a$ con la versión de Menéndez Pidal (1b), comprobamos que en la transcripción moderna prevalece

\footnotetext{
Gentil dona, gentil dona, dona do bell paresser, los pes tingo en la verdura esperando oato plaser. Por hi passa l'escudero mesurado e cort6s; les paraules que me dixo todes oren d'emores: - Tatc, escidero, este coerpo, esto corpo a tu plaser, les tetilles ugudilles qu'el brial queran fender. Alli dixo l'escudero: - No es hora de detener,

la muller tingo fermosa, figes he de inantener.

ol ganado en lu sicrra quo so me va a porder.

- Alli vagus, mal villano, Dious to quern mal feser...
}

FIG. 1a.-Romance de una gentil dama y un rústico pastor (versión mallorquina de Jaume de Olesa. 1421). Es el romance manuscrito más antiguo que se conserva. FIG. 1b.--Transcripción de Menéndez Pidal, Romancero Hispánico, I, p. 341.

c) representación de pausa tras un grupo fónico en la trascripción de los romances u otros géneros de poesía.

40 M. DÍAz ROIG, ibid., p. 80, núm. 20, v. 5.

i1 Cf. R. MENÉndez PidAl, op. cit., I, pp. 92-94.

42 Quizá por ello, quienes editan algunos romances en octosilabos, como A. CARRIL, lo hacen así por tratarse de canciones que llevan un estribillo tras cada octosílabo; más por analogía con la canción lírica que por una razón filológica. Cf. Canciones y romances de Salamanca (2. ${ }^{a}$ ed.) (Salamanca: Librería Cervantes, 1992). 


\author{
Yome enaparepofalioo \\ ourmicnoo como folk \\ reco:oetrine llesanoo \\ con granpenequerentis \\ Lerailte mie mup in nento \\ oclocamia en que cormia \\ cercadoos penfainicilto \\ qule valer nome posin \\ ani pafioneratan fucte \\ quic oe mi ponorabio \\ comigo effavala muerte \\ postenerme companiia \\ Zoquemesmefongors \\ no cra poz que muria \\ maserapoz que ocsura \\ oefervir a quien fervila \\ Eerria yo vna fefio:a \\ quc mes \& a milo queria \\ rello fue lacaufapo:a \\ oe mimal nn mejoris \\ zomicoia necbe pefraco \\ rẵ crocersa oel oio \\ ralime oe mi poreos \\ por vernioefconfaria \\ Sup pars sonse mo:0po \\ oquella quemooqueria \\ po:quien fornfepellara \\ niesells isoparccia \\ Znoundo 1000 turbilos \\ con las anfias que temia \\ vivenir a ini cuyodoo \\ oanco bojca p ocjla \\ Ei on:Inislineafriots \\ reco:s0o po: cortefis \\ puesque fuciles caursoo:a \\ ocla ocrocntura inis \\ Remiediasulini gran srifurs \\ raficfasco ini pusfia \\ pez que fifaliea ventura \\ ocl rosome peroerna \\ $Y$ con mizojos lls:oros \\ rnirifie llailis basia \\ con rolpiros congorolos \\ y uidoic us paresid \\ Encrassilytasinanos \\ ramovinie cfllarecia \\ - ini cafáarpirunoo \\ me holrifin alesna.
}

FIG. 2.-Juan del Encina, Romance del enamorado y la muerte (Cancionero de Encina; Salamanca, 1496). 


\section{IT Romançe oe amadis y oztanay

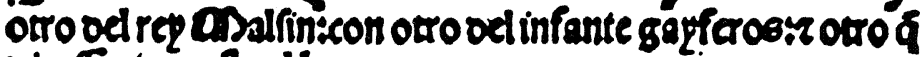 oizeren ken dits el buen rep.con otros 000 rommece.}

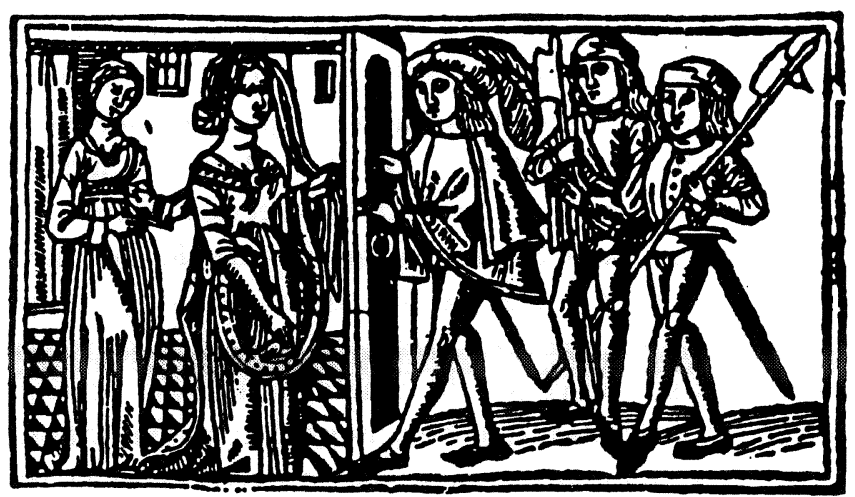

Jumabis cl mury famolo bilo od buen req oe gaula que amozes fuctorn 100 pfos con la nupplinos artans Lila oel req lifiarte Teñoz oclaggranbretaña que famas poz penfamiento nunca el mo al otro ctrars fi bna pes que fue oeforitba pozla requa briolania Driana temia celos y cierto mal lo penfauta mucbola querta amads mas cra amoz oe bermana

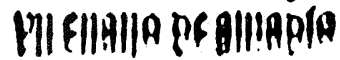
al reuce efto tomaus segun fe nucrian loo 000 a crella böbie no babiraus

clamos los congufftans rupolo oesquestectrano la princefa oxiana tanto cholo refabto quel cosacon le llosausa Dians con gran perta ons carrale embrara que fe fuere oo no lo viere que famas verlo penfaus quanoo amadis la lezro el coloz sele muloara peroiera tooo cl fentroo muy granoes forpiros oalls apartofe ocl camino parepormia moniañ la qual cra muy elpefla

FIG. 3.-Romance de Amadís y Oriana (pliego suelto del siglo XVI). 
el criterio lógico que individualiza la unidad sintáctico-semántica (aparte de las consideraciones históricas sobre el origen épico del romance). Adviértase que en $1 b$ no hay marca gráfica de la cesura, ni de la unidad fónica y métrica que constituye el octosilabo.

Realmente, los dos criterios - verso de ocho o de dieciséis sílabasreflejan dos tendencias rítmicas de la lengua oral a las que nos hemos referido anteriormente. El texto antiguo asigna una sola línea a la unidad recitativa mínima del romance, el octosilabo, cuyo ritmo es afín al ritmo mismo de la lengua. La transcripción moderna, al considerar como unidad el verso que contiene dos octosílabos, refleja la tendencia rítmica de la poesía oral y de los proverbios hacia lo que Sánchez Romeralo llama el movimiento binario: "digo A y añado $\mathrm{B}^{4}{ }^{43}$. Para este mismo autor ${ }^{44}$, al volver a los orígenes con la tirada larga de dieciséis sílabas, "contradiciendo la historia gráfica conocida del romance - desde los pliegos más antiguos, hasta los grandes poetas de los siglos áureos, y, después, los del $\mathrm{xx} \longrightarrow$, se le devolvió "al discurso verbal del romance su verdadera forma "oral". Que ésa es su forma oral lo prueba una razón prosódica en nada desdeñable: el dieciseisilabo, que constituye una unidad rítmica, sintáctica y de contenido, es también una unidad de respiración; la respiración es la que requiere una pausa, y esta pausa es la que individualiza cada verso. El recolector percibe a menudo que a esa entonación monótona con la que el recitador tradicional va desgranando sus versos se le suma la regularidad de una inspiración realizada, únicamente, antes de cada dieciseisilabo, inspiración que llega a formar parte del acto de palabra de la recitación, de su propio ritmo, al que concurren, pues - en lo vocalmetro, rima, entonación y respiración.

4.1.4. Cuando la unidad sintáctico-semántica completa que constituye la frase se extiende a cuatro octosílabos y cuando a esta unidad le corresponde asimismo una unidad melódica de cuatro frases musicales, en algunas ocasiones se da una marca gráfica de tal unidad.

En el texto 2, el impreso de un romance de Juan del Enzina, la marca gráfica es una mayúscula inicial de frase al comienzo de cada cuarteta, lo mismo que en el texto que sigue, tomado de una edición actual de divulgación de canciones populares; el romance se presenta en dísticos de dieciseisílabos separados por un doble interlineado. En ambos casos se está transcribiendo el texto pensando en la música: la música de dos frases es la de tradición más antigua, épico-juglaresca; mientras que la de

43 Cf. nota núm. 9.

44 "La edición del texto oral", op. cit., p. 69. 
cuatro frases es la de tradición más moderna, iniciada en la época renacentista y cortesana.

El Emperador de Roma, tiene una bija bastarda que la quiere meter monja, y ella quiere ser casada.

La ha metido en un convento, por ver si la resguardaba $y$ el resguardo que ba tenido, que ba salido embarazada.

$A$ los calores del dia, se ba asomado a una ventana $[\ldots]^{45}$

\subsection{Textos sin puntuar}

Dos de los hechos citados hasta aquí constituyen algunas de las razones por las que Ana María Martins ${ }^{46}$, en razón de una mayor fidelidad a la tradición transmitida, ha propuesto que no se empleen signos de puntuación convencional en la transcripción de textos romancísticos.

En primer lugar, las unidades métricas y recitativas y sus pausas vienen ya representadas gráficamente por la línea y el espacio en blanco. En segundo lugar, las diferencias de entonación entre las frases quedan neutralizadas: en el texto cantado, porque toda melodía sustituye a la entonación de la lengua hablada; en el texto recitado, por el tipo de prosodia plana al que nos referimos anteriormente.

Veamos algunos ejemplos de los propuestos por esta autora:

$\begin{array}{ll}\text { Estavam dois tiranos } & \text { cada um a sua esquina } \\ \text { Viram duas meninas } & \text { qual era a mais linda } \\ \text { Dizia um para outro } & \text { qual era a que lhe convinha } \\ \text { Aquela de azul claro } & \text { esta noite bá-de ser minha }{ }^{47}\end{array}$

A. M. Martins observa que en el Romanceiro Português de Leite de Vasconcelos, los editores de este romance optaron por considerar como interrogativa la frase qual era a que lhe convinha, tomándola como intervención de uno de los personajes e interpretando como respuesta a esta posible pregunta la frase: Aquela de azul claro esta noite há-de ser minha. Pero, para la mencionada autora, esta frase no necesita tener como soporte una pregunta anterior, razón por la que el verso:

45 A. CARRIL, op. cit., p. 130; La bastarda y el segador, vv. 1-5.

46 "A edição de romances e o problema da pontuação", De Balada y Lírica, 1. Tercer Coloquio Internacional sobre el Romancero (2 vols.), (Madrid: Editorial Complutense y Fundación Ramón Menéndez Pidal, 1994), I, pp. 359-373.

47 Ibid., p. 370; Os Soldados Forçadores. 
Dizia um para outro qual era a que lhe convinba

admite perfectamente una modalidad afirmativa, prolongándose hasta el final del verso, de este modo, el discurso del narrador. En un caso como éste, ¿qué solución adoptar? - se pregunta A. M. Martins-. Su propuesta es la de no ignorar, sino mantener la ambigüedad que existe como factor intrínseco del texto.

Otro ejemplo: en el Conde Alarcos — sigue diciendo A. M. Martins ${ }^{48}$ el hemistiquio Ai Jesus! Quem morreria? es normalmente transcrito con signo de exclamación y signo de interrogación. Sin embargo, según el testimonio de esta recolectora, en casi la totalidad de las versiones de este romance recogidas por ella, no registró pausa exclamativa alguna, ni fue audible una entonación ascendente al final del verso.

La propuesta, tan bien fundamentada por la estudiosa del Romancero portugués, no es en absoluto el único testimonio de relación entre texto oral y ausencia de puntuación, porque antiguamente, con frecuencia, tampoco se puntuaban los textos en verso. Si se hacía, era a menudo de modo irregular y sin la aplicación de un criterio fijo para un mismo texto, como podemos comprobar en 3, texto facsimilar de un pliego del siglo $\mathrm{xvI}$, en el que se constata un empleo asistemático de la mayúscula con valor de diferenciación entre nombre común y nombre propio, así como el uso de diversos signos de puntuación en el título, en tanto que faltan por completo en el texto.

La ausencia de puntuación en muchos de los textos antiguos en verso, manuscritos e impresos, parece ser un indicio de la recepción oral a la que estarían destinados dichos textos. Si el empleo sistemático de la puntuación está ligado al desarrollo de la lectura individual y a una cultura del libro y de la imagen visual del lenguaje, los textos sin puntuar nos remiten a unas prácticas de divulgación de la literatura en las que la oralización de los textos sigue estando en vigor, y no en oposición, sino en un particular equilibrio, con respecto a los valores de la cultura de transmisión escrita ${ }^{49}$.

Parece apoyar tal consideración la siguiente reflexión lingüística: las estructuras fónicas suprasegmentales de la lengua oral y sus correlatos gráficos, los signos de puntuación, poseen, en ciertos casos, un valor distintivo. Los enunciados

48 Ibid., p. 371.

49 Sobre la conciencia común de la oralidad del Romancero en la Edad de Oro y el paso a la lectura colectiva o individual de los romances impresos, cf. M. ${ }^{a}$ C. GARCía DE ENTERRíA, "Romancero: cantado-recitado-leído", Edad de oro, 7 (1988), pp. 89-104. 


\section{¿Elena, escucha! Elena escucha? Elena escucha.}

por ejemplo, son diferenciados por la entonación y la pausa en la oralidad, o bien, por la coma y los demás signos en la escritura. Además de ese valor distintivo, se ha de señalar el hecho de que los patrones prosódicos del código oral y los signos de puntuación del código escrito son los recursos de la lengua que permiten actualizar la secuencia fónica [elenaeskuţa] y la secuencia gráfica <elenaescucha> ${ }^{50}$.

En un planteamiento inverso -que ejemplificamos con los textos $4 a$ y $4 b$, de un manuscrito del Libro de Buen Amor del siglo $\mathrm{XIV}^{51}$-, en la medida en que el texto no es inscrito con signos gráficos que sustituyan a ciertos patrones entonativos, dicho texto se presenta como un discurso no actualizado en algunos aspectos. Para actualizarlo se presentan dos vías.

Primera vía: una reescritura del texto en la que los signos gráficos representen pausas y entonaciones, o, simplemente, organicen la sintaxis según usos ya propios de la escritura. Es la solución adoptada por los editores modernos de los textos medievales, quienes los puntúan para permitir una transmisión y una comunicación escritas, puesto que sus ediciones están destinadas a un público con unos hábitos de lectura mayoritariamente silenciosa, en la que se retiene una imagen visual del texto. Puntuar el texto antiguo conlleva, por supuesto, una interpretación del mismo en ciertos aspectos.

La segunda vía de actualización es una oralización del texto, modo de comunicación de la literatura que era el más frecuente en la época de escritura del verso sin puntuación. Tal solución supone también una interpretación de los textos.

En nuestra opinión, la ausencia de signos de puntuación en el sistema antiguo de escritura del verso obedece al hecho de que tal sistema

50 Cf. N. CATACH, "La ponctuation", Langue Française, 45 (1980), p. 24 y La ponctuation (Paris: PUF, Col. "Que sais-je?", 1994), p. 103.

51 Códice de Salamanca, firmado por su copista, Alfonso de Paradinas, y fechado en 1343. Los únicos signos de puntuación empleados en este manuscrito son la mayúscula inicial de estrofa y la virgula simple (/) o doble (//), que marca la cesura, aunque de modo irregular, pues si en algunos folios se marcan todas las cesuras, en otros no se emplea marca alguna. Ni a final de verso, ni en el interior de ningún hemistiquio se emplea signo alguno de pausa. Juan Ruiz, Arcipreste de Hita. Libro de buen amor. Vol. I: Edición facsímil del códice de Salamanca. Ms. 2.663. Vol II: Estudio histórico-crítico y transcripción textual del códice de Salamanca por César REAL DE LA RIVA (Madrid: Universidad de Salamanca-Edilán, 1975). 
contaba previamente con la realización oral del texto para completar toda su información lingüística ${ }^{52}$.

Veamos en la transcripción de algunos versos del Libro de Buen Amor, por ejemplo, la parte de interpretación que implica la puntuación del manuscrito.

En $4 a$, la puntuación elegida por el editor es la siguiente:

Un omne grande, fermoso, mesurado a mi vino;

yo le pregunte quien era. Dixo: "Amor, tu vezino" ${ }^{53}$.

El manuscrito se podría haber interpretado de otro modo: Dixo Amor: "Tu vezino". Sólo la entonación en la oralidad o el criterio de puntuación elegido en la escritura deciden sobre la versión definitiva. Lo importante es que es necesario uno de los dos procedimientos para actualizar los enunciados.

Para $4 b$ se da la transcripción:

Mesquino, ¿tu que faras el dia de la afrenta,

quando de tus averes e de tu mucha renta

52 Desde una perspectiva antropológica, M. MCLuHAN señaló la idea de que la ausencia de puntuación de los textos está en relación directa con la necesidad de una oralización de estos mismos. The Gutenberg Galaxy: The Making of Typographic Man (Toronto: University of Toronto Press, 1962). La idea sigue siendo admitida por la antropología y ha sido desarrollada con posterioridad, cf., por ejemplo, W. ONG, Orality and Literacy. The Technologizing of the Word (Londres - Nueva York: Methuen, 1982), p. 119; P. ZUMTHOR, La lettre et la voix. De la "littérature"médiévale (Paris: Seuil, 1987), p. 118; P. SAENGER, "La separación de las palabras y la fisiología de la lectura", Cultura escrita y oralidad, comps. D. R. OLSON y N. TORRANCE, traducción de G. Vitale (Barcelona: Gedisa, 1995), pp. 263-284. Tal idea no excluye la posibilidad de que, también, en diferentes épocas, la eliminación voluntaria de la puntuación en el verso haya sido practicada con el fin de provocar una atenta lectura mental y únicamente visual. Es evidente, por otra parte, que el texto en verso requiere menos puntuación que el texto en prosa: el sistema rítmico de la poesía oral que asigna a cada verso una unidad sintáctica (sistema de la épica medieval, del Romancero y de la poesía medieval concebida para la lectura en voz alta) indica ya con el cambio de línea una frontera sintáctica que, en la oralidad, viene marcada por el fin del verso, esto es, por la consumación de su número de sílabas marcada por la rima. Véanse al respecto las reflexiones de J. Polo. Ortografia y ciencia del lenguaje (Madrid: Paraninfo, 1974), pp. 107-110, sobre una "puntuación suelta" frente a una "puntuación trabada", paralelas a la "sintaxis suelta" y a la "sintaxis trabada" de las que hablaban D. Alonso, "Estilo y creación en el Poema del Cid", Ensayos sobre poesia española, Revista de Occidente (1944), pp. 69-111; y A. M. BADÍA MARGARIT, "Dos tipos de lengua cara a cara", Studia Philologica, Homenaje ofrecido a Dámaso Alonso (Madrid: Gredos, 1960), I, pp. 115-139.

53 C. REAL DE LA Riva, ed., vol. II, p. 28, estr. 181, vv. 3-4. 
te demandare Dios de la despenssa cuenta?;

non te valdran thesoros, nin reynos cinquenta ${ }^{54}$.

Pero la interpretación podría haber sido otra; por ejemplo:

\author{
Mesquino, ¿tu que faras el dia de la afrenta? \\ Quando de tus averes e de tu mucha renta \\ te demandare Dios de la despenssa cuenta, \\ non te valdrán thesoros, nin reynos çinquenta.
}

El texto sin puntuar es, en cierta medida, un texto aún abierto a una interpretación del lector o del editor moderno.

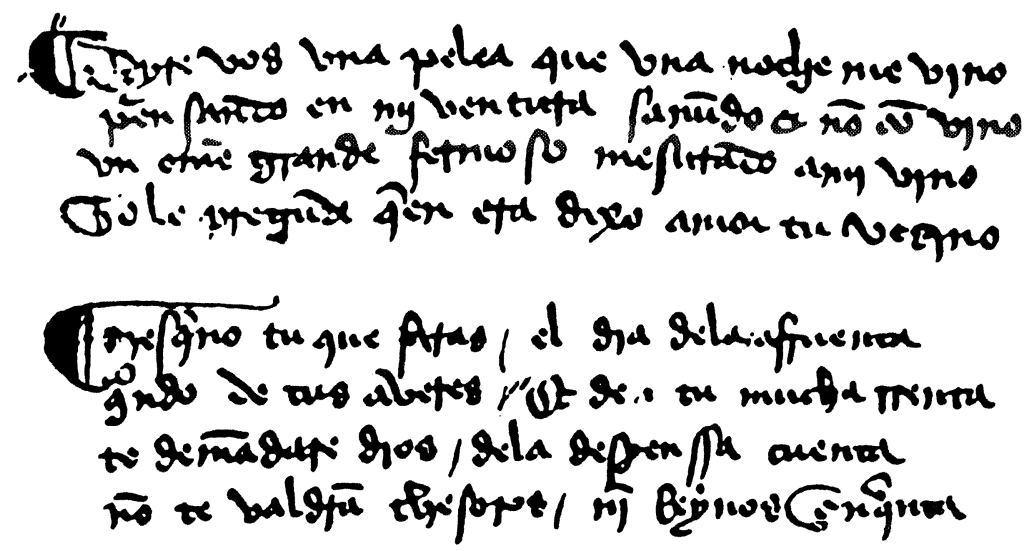

FIG. 4a y b.-Libro de Buen Amor, Códice de Salamanca (MS. 2663, f. 13v, estr. 181 y f. 184, estr. 249).

Sirva de ejemplo de transcripción sin puntuar de un texto oral el romance manuscrito más antiguo que se conserva (texto 1a): éste no posee signo de puntuación alguno, salvo la mayúscula inicial. La escritura es aquí testimonio y recordatorio del texto memorizado por Jaume de Olesa, quien buscó una conservación escrita fija del texto que siempre había sido y habría de ser transmitido oralmente. La transcripción de Menéndez Pidal (1b), al contrario, está destinada a una conservación escrita y a una transmisión únicamente visual, para la cual, la escritura aporta un sistema propio de signos con valor sintáctico o de marca de tipo de discurso, etc.

54 Ibid., p. 37, estr. 249. 


\subsection{Textos con puntuación sin correspondencia prosódica}

4.3.1. Puntuación de frase.-A. M. Martins ${ }^{55}$, en su citada propuesta de no puntuar las transcripciones modernas de los textos romancísticos orales, pone en duda la coherencia de la diversidad de los signos de puntuación convencional empleados a final de verso, porque, desde el punto de vista prosódico, los signos presuponen graduaciones de duración en la marca de pausa que no tienen realidad en el nivel de la recitación, ya que el fin del verso conlleva siempre el final de la frase. Por otra parte, dicha autora señala ${ }^{56}$ que los signos de puntuación que encontramos en el interior del octosílabo son sólo indicaciones para el lector, puesto que en el interior del hemistiquio los informantes nunca hacen pausas recitativas.

La autonomía de la unidad métrica es sentida frecuentemente por los editores de textos romancísticos, por lo que se observa en algunas ocasiones una tendencia -que no criterio sistemático- a la omisión de la coma normativa, cuando ésta coincide con la cesura, pues la cesura conlleva una pausa cuya marca gráfica aparece ya, en algunas ediciones, en el doble espacio en blanco. (En realidad, en este caso, la puntuación convencional se muestra redundante respecto al espacio en blanco).

Ocurre en el caso de repeticiones del tipo:

$$
\text { A la verde verde a la verde oliva }{ }^{57} \text {, }
$$

en las que no siempre se omite la coma:

$$
\text { Un dia fue a la fuente, a la fuente fría }{ }^{58} \text {, }
$$

Y en el caso de proposiciones relativas explicativas:

$$
\begin{aligned}
& \text { la muller tingo fermosa, figes be de mantener, } \\
& \text { el ganado en la sierra que se me va a perder }{ }^{59} \text {. } \\
& \text { Un dia fue por agua a la fuente fria } \\
& \text { y vio a un anciano que de ella bebia }{ }^{60} .
\end{aligned}
$$

55 Op. cit., p. 365.

56 Ibid., p. 361.

57 GC II, 61.1, v.1.

58 GC II, 61.1, v. 11.

59 R MENÉNDEZ PIDAl, op. cit., I, p. 341, Una gentil dama, vv. 8-9.

60 GC II, 6.2, vv. 11-12. 


$$
\begin{aligned}
& \text { La pícara mora que las escucbó } \\
& \text { abrió una mazmorra y las encerró }{ }^{61} \text {. }
\end{aligned}
$$

En los textos puntuados no se suele omitir, sin embargo, la coma de las distribuciones:

$$
\begin{array}{ll}
\text { - iYa sabes, Constanza, } & \text { ya sabes, Lucía, } \\
\text {-No llores, Constanza, } & \text { no llores, Lucia, }{ }^{62}
\end{array}
$$

ni la coma de los vocativos y aposiciones, aunque el octosílabo se presente en la recitación como unidad prosódica sin pausas interiores.

$$
\text { -No me mate, caballero, no mate lo que Dios cría }{ }^{63} \text {. }
$$

En este caso, la coma es una imposición de la ortografía, que sigue un criterio lógico, según la función sintáctica de los elementos de la frase, aunque no tenga correlato prosódico de pausa en la recitación ${ }^{64}$.

4.3.2. El guión como marca de discurso directo.-La mencionada editora, A. M. Martins ${ }^{65}$, propone no emplear el guión como marca de inicio del discurso directo, puesto que éste es un signo gráfico sin realidad en el nivel prosódico. Muchas veces, en el texto oral, no se sabe quién profiere las palabras e, incluso, las fronteras entre el discurso directo y la narración permanecen opacas ${ }^{66}$. Para Martins, estas ambigüedades existentes respecto a la identificación del sujeto del discurso son intrínsecas del propio romancen. Por esta razón, en efecto —como apunta también M. Débax ${ }^{67}$-, atoda puntuación es ya una lectura" y "elegir es ya interpretar".

61 GC II, 61.2, vv. 23-24.

62 GC II, 61.2, vv. 17 y 21.

63 GC II, 4.23, v. 10.

64 No sólo en la recitación, sino en la lengua común, en español no existe pausa tras algunos vocativos. "En las respuestas corrientes: "Sí, señor", "No, señor", "Sí, hombre!", etc., no se hace nunca pausa donde se marca la coman. A. ROSENBLAT, Fetichismo de la letra (Caracas: Universidad Central de Venezuela, Cuadernos del Instituto de Filología "Andrés Bello", 1963), p. 60. También lo señalaba T. NAVARRo TOMÁs en Manual de pronunciación española (Madrid: CSIC, Publicaciones de la RFE, 21. ${ }^{a}$ ed.: 1982, p. 217.

65 Op. cit., pp. 367-369.

66 Cf. M. DÉBAX, "La problématique du narrateur dans le Romancero Tradicional", Sujet et sujet parlant dans le texte (textes hispaniques). Actes du Colloque du Séminaire d'Etudes Littéraires de L'Université de Toulouise-Le Mirail (Publications de l'Université de Toulouse-Le Mirail, 1977), p. 48.

67 "En torno a la edición de romances", La edición de textos. Actas del I Congreso Internacional de Hispanistas del Siglo de Oro. Ed. de P. JAURALDE, D. NOGUERA y A. REY (Londres: Tamesis Books Limited, 1990), p. 52. 
Algunos editores han seguido, de modo más o menos consciente y sistemático, el criterio de no emplear el guión de discurso directo en la transcripción de textos orales, como, por ejemplo, el editor del siguiente romance cantado:

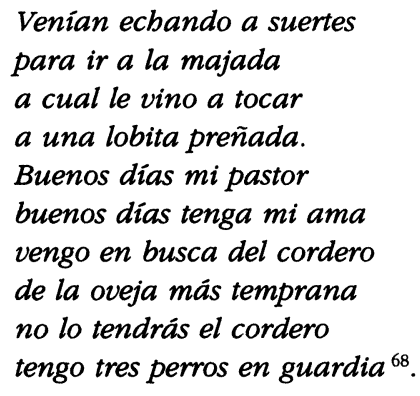

La fidelidad a la imprecisión del texto oral va en detrimento de la legibilidad del texto escrito, que es lo que va a recibir el nuevo receptor del romance, el lector. A éste le es difícil identificar qué parte de discurso corresponde a cada personaje; ha de volver atrás, releer el texto e interpretar el pasaje. Una versión puntuada ofrecería una clara interpretación del texto a primera vista; ahora bien, el modelo de texto puntuado se presta a varias versiones:

Venian echando a suertes para ir a la majada, a cual le vino a tocar a una lobita preñada. - Buenos días, mi pastor.

-Buenos días tenga, mi ama.

- Vengo en busca del cordero,

de la oveja más temprana.

- No lo tendrás el cordero; tengo tres perros en guardia. b

Venian echando a suertes para ir a la majada. ¿A cuál le vino a tocar? A una lobita preñada.
Venian echando a suertes; para ir a la majada ¿a cuál le vino a tocar? A una lobita preñada.

En razón de las nuevas necesidades de la transmisión escrita, el editor se ve en la necesidad de interpretar los textos orales y de puntuarlos, aunque los signos empleados no tengan una correspondencia prosódica.

El guión de diálogo, como marca de inicio del discurso en estilo directo, es un signo sin correspondencia sonora, empleado por el editor como ayuda a la lectura. El sistema de la escritura ordena la lengua con

68 A CARRIL, op. cit., p. 110; El cantar de la zamarra, vv. 5-14. 
recursos adaptados a su medio de transmisión visual; tal sistema diferencia mediante signos de puntuación los tipos de estilo del discurso, aunque éstos no estén marcados por diferencia prosódica alguna en el romance recitado que se ha de transcribir.

4.3.3. Signo de interrogación.-Por la neutralización de las diferencias de entonación a la que nos hemos referido anteriormente, el signo de interrogación que los editores emplean es únicamente, en la mayoría de los casos, un indicador del sentido interrogativo de una frase, pero no representa cambio alguno de entonación en la recitación o en el canto.

Efectivamente, en el canto, lo que oímos son enunciados que sólo podríamos transcribir del siguiente modo:

$$
\begin{aligned}
& \text { tú te quieres ir conmigo bacia el monte de la oliva } \\
& \text { y la ropa que yo lavo dónde yo la llevaría }
\end{aligned}
$$

Sin embargo, el editor interpreta el texto; atribuye a cada personaje una frase y a cada frase un sentido, para dar al lector una versión escrita de lectura fácil.

$$
\begin{aligned}
& \text { - ¿Tú te quieres ir conmigo hacia el monte de la Oliva? } \\
& \text { _Y la ropa que yo lavo dónde yo la llevaria? }
\end{aligned}
$$

\section{CONCLUSIONES}

De todo lo expuesto, nos interesa destacar tres consideraciones:

5.1. Reflexionar sobre el paso de la voz a la letra del romance supone -como cuestión general- revisar la especificidad de los sistemas de comunicación oral y escrita, de los dos códigos en que se manifiesta la lengua. Supone -en lo que concierne a una Poética de la oralidad y a la Poética del Romancero-, volver a pensar el romance como un acto completo de palabra viva y explicitar en qué esa palabra es un arte vocal.

Hacemos nuestra, con pleno convencimiento, la afirmación de Sánchez Romeralo: "La cuestión de cómo transcribir un "texto" originariamente oral no es pues trivial ni puramente tipográfica. Es una manera de enfrentarse seriamente al texto y a la realidad poética oral en que ese texto se inserta. Lo primero será, pues, comenzar por entender esa realidad oral, si

69 GC I, 4.3, vv. 8-9. 
queremos, en la medida en que sea posible, representarla, o representarla mejor" ${ }^{70}$.

5.2. Está por estudiar la prosodia del Romancero oral, es decir, una parte de la tradición poética, que ha quedado fuera de las transcripciones.

La etnografía se ha ocupado del medio sociocultural en que perviven los romances, de los transmisores, de los receptores, de la función social, etc. La filología ha estudiado los textos en su historia, sus temas, su funcionamiento en la tradición, sus recursos lingüísticos, etc. La musicología se ha ocupado de las melodías, de los modos y medios de interpretación, etc. Pero existe un vacío en el estudio sistemático de la voz del Romancero recitado. Sirvan las reflexiones de este trabajo como base para un estudio que debería responder a cuestiones como las siguientes: ¿Existen constantes en la recitación? ¿Qué tipología se puede establecer? ¿Qué valores comunicativos y culturales tiene cada modalidad? ¿Qué relación tienen con la tradición? ¿Qué temática de romances es propia de la recitación y en qué ámbitos geográficos? ¿Cuál es la importancia cuantitativa del Romancero recitado en la actualidad y en el pasado? ${ }^{71}$ ¿Qué modos de transcripción de la prosodia se han empleado y podrían emplearse? etc, etc.

5.3. Diego Catalán señala que: "al apropiarnos, como colectores y lectores de romances, el papel de receptores o destinatarios de los mensajes que esos romances expresan (no siéndolo realmente, puesto que estamos fuera de la cadena de transmisión constituida por los sucesivos portadores de saber tradicional), nuestro objetivo debe ser intentar reproducir, simular, la actividad recognoscitiva, descodificadora, de los consumidoresproductores del romancero" 72 .

Indudablemente, y por referirnos sólo al campo de la "competencia", el proceso de puntuación de un texto oral supone reproducir y simular la actividad recognoscitiva que, por ejemplo, atribuye en la oralidad un sentido interrogativo o declarativo a una frase, o que atribuye un enunciado a uno u otro personaje; simulación de la actividad descodificadora, que se realiza en la escritura por medio de signos de interrogación, guiones, comas, etc.

70 "La edición del texto oral", op. cit., p. 71.

71 Cf., por ejemplo, M. TRAPERo, "Cómo vive el romancero en Gran Canaria (Resultado de una encuesta), Anuario de Estudios Atlánticos, 31, (1985), p. 21.

72 "El Romancero, hoy", Boletín Informativo de la Fundación Juan March, 133, Enero (1984), p. 8. La cursiva es nuestra. 
El editor, que está ya fuera de la cadena de la transmisión tradicional, se presenta así como una figura que debe interpretar ciertos aspectos de los textos orales y que sirve de intermediario entre el recitador o cantor y el futuro lector, el cual se hallará más alejado aún del texto oral y de su contexto natural.

El texto oral funciona en el seno de un grupo sociocultural limitado; es texto "presente" y para el tiempo presente: su necesidad de comunicación no tiende a la universalidad; mientras que la escritura, con una recepción atomizada entre tantos lectores individuales, ha de moverse en el nivel de lo general y de lo abstracto ${ }^{73}$. El texto escrito es texto que mira al futuro. En ese paso de la oralidad a la escritura, el editor de romances debe atender, por una parte, a la fidelidad en la conservación del texto, $\mathrm{y}$, por otra, a la perfecta actualización y transmisión escritas del mismo; misión ésta por la que el editor asume realmente un papel de intérprete del lenguaje de los romances.

\author{
MAXIMIANO TRAPERO \\ Universidad de Las Palmas de Gran Canaria \\ ELENA Llamas POMBO \\ Universidad de Salamanca
}

El editor de relatos orales encuentra ciertos problemas al tener que convertir en texto escrito lo que en origen era discurso oral. El texto sometido a tal mutación cambia de naturaleza y de función; porque lo que era palabra individual, acto en presencia, lenguaje con una función social determinada (expresividad lúdica, memoria de mitos y arquetipos, testigo vivo y creativo de la tradición), todo ello se convierte en escritura: lenguaje sin voz, destinado a la lectura individual y dotado de una función, no menos importante, de testigo erudito y perdurable en el tiempo de la tradición. Si la escritura es un sistema que intenta representar la lengua, ¿la puntuación del texto transcrito representa realmente la prosodia del relator?, ¿es aportación exclusiva del editor, que debe ofrecer una nueva versión escrita? Examinaremos aquí los criterios de puntuación que, buscando siempre la mayor fidelidad al relato oral, han adoptado diferentes editores de textos del Romancero hispánico.

The editor of oral narratives must face certains problems when turning what was originally oral discourse into a written text. The original narrative changes its nature and function as a result of this transformation: the individual word, the performing act, language with a specific social function - playful expressiveness, as well as living and creative preservation of myths, archetypes and tradition- becomes writing, that is, language with

73 P. ZUMTHOR, Introduction à la poésie orale (Paris: Seuil, 1983), p. 40. 
no voice, intended for individual reading, and endowed with a different, although no less important, function as a learned and enduring witness to those myths, archetypes and tradition. If writing is a system which attempts to represent language, does the punctuation in the transcription of the oral really represent the narrator's prose, or, on the contrary, is this punctuation exclusively the editor's contribution, narrative thus creating a new written version? In this article, the author examines the punctuation guidelines adopted by different editors of traditional Hispanic ballads - romances in Spanish - in their search for the most faithful rendering of the oral narrative. 